\title{
Synthesis of glycosaminoglycan in adult human articular cartilage in organ culture from patients with rheumatoid arthritis
}

\author{
R. K. JACOBY AND M. I. V. JAYSON \\ From the Department of Medicine, Bristol Royal Infirmary, University of Bristol, \\ and the Royal National Hospital for Rheumatic Diseases, Bath
}

\begin{abstract}
Jacoby, R. K., and Jayson, M. I. V. (1976). Annals of the Rheumatic Diseases, 35, 32-36. Synthesis of glycosaminoglycan in adult human articular cartilage in organ culture from patients with rheumatoid arthritis. Hyaline cartilage was obtained from patients undergoing synovectomy of the knee joint for rheumatoid arthritis. Eroded cartilage from beneath the invading pannus and relatively normal cartilage from the same joint were maintained in organ culture for three days. During the first 48 hours in culture the explants were exposed to ${ }^{35} \mathrm{SO}_{4}$ in the medium. The equivalent layers of normal and eroded cartilage were analysed for DNA uronic acid and ${ }^{35} \mathrm{SO}_{4}$ incorporation. There was a decrease in the DNA and uronic acid of the eroded cartilage, although only the latter reached statistical significance. The uptake of radioactive sulphate was significantly greater in explants taken from the eroded site than from normal areas. This increase in metabolic activity could well be a protective phenomenon.
\end{abstract}

Normal cartilage is impermeable to large molecules and in particular to immunoglobulins (Maroudas, 1970; Poole, Barratt, and Fell, 1973) and therefore has a somewhat privileged position in the body. Millroy and Poole (1974) have shown that if normal pig cartilage is damaged and the chondrocytes remain viable they are able to reform a protective capsule of metachromatic material. In osteoarthrotic cartilage there is depletion of glycosaminoglycan with an increase in metabolic activity of the chondrocytes (Mankin and Lippiello, 1970). Articular cartilage is destroyed in rheumatoid arthritis by the invading pannus and recent studies have shown that the enzyme depletion of the cartilage matrix allows large molecules to enter the tissue (Millroy and Poole, 1974). It is therefore relevant to investigate the activity of the chondrocytes in cartilage that has been eroded by rheumatoid pannus and compare it with chondrocytes in unaffected sites.

\section{Material and methods}

The articular cartilage was taken from patients at operation for synovectomy of the knee joint. The cartilage was sliced parallel to the articular surface from the edge of an area of pannus to include eroded and noneroded areas only where such an area was lateral to the patellar articulation.
Normal cartilage was included in the same slice as the eroded cartilage, so as not to damage the articular surface more than $5 \mathrm{~mm}$ from the invading pannus. The cartilage was placed immediately into tissue culture medium BGJ5 (Biggers, Gwatkin, and Heyner, 1961; Reynolds, 1972) and transported to the laboratory at room temperature and cultured after the method of Trowell (1954), as modified by Dingle, Fell, and Lucy (1966). The cartilage was cut into cylindrical explants using a sterile hollow biopsy needle having an internal diameter of $3 \mathrm{~mm}$. The explants were maintained for 48 hours in contact with medium BGJ5 with $5 \%$ fetal calf serum and $10 \mu \mathrm{Ci}$ ${ }^{35} \mathrm{SO}_{4}$. The cultures were gassed with $20 \%$ oxygen, $5 \%$ $\mathrm{CO}_{2}$, and $75 \%$ nitrogen. Cultures were then lifted off the culture grids and washed in a stream of nonradioactive medium for a further 24-hour culture period. The specimens were maintained at $37^{\circ} \mathrm{C}$ and control cultures at $4^{\circ} \mathrm{C}$.

At the end of the culture period the explants were frozen and divided into $10 \mu \mathrm{m}$ sections on a cryostat. Consecutive sections were collected into groups of $\mathbf{5 0}$ for analysis and as the explants were all cylindrical the sections were of comparable size. The surface 40 sections from the noneroded cartilage were not included for analysis since this layer had been destroyed by the invading pannus in eroded explants. It is important that equivalent layers are compared since in normal cartilage the surface layers differ from the deeper ones both in structure and metabolism (Jacoby and Jayson, 1975b). The 
groups of sections were labelled A, B, C, to identify the zone from which they had been taken. For the noneroded explants the first section in batch A was No. 41 from the surface, whereas in the eroded explants the first section in batch $\mathbf{A}$ was the top section taken from the block. This agreed with preliminary observations of similar eroded cartilage indicating erosion of about $0.4 \mathrm{~mm}$.

The sections were washed in three changes of ethanol containing $0.1 \%$ sulphuric acid, and digested in $1 \mathrm{ml}$ of buffered papain (twice crystalized papain (Sigma) $10 \mu \mathrm{l}$ EDTA $0.744 \mathrm{mg}, \mathrm{N}$-acetyl cysteine $0.326 \mathrm{mg}$ phosphate buffer $0.5 \mathrm{~mol} / \mathrm{l}$ ) at $60^{\circ} \mathrm{C}$ for 3 hours. The digest was then divided into aliquots for scintillation counting, DNA content, and uronic acid determination. The radioactive uptake was measured on $50 \mu$ l digest with $0.25 \mathrm{ml}$ formic acid and scintillation cocktail: Triton $\times 1$ part (Sigma) NE 2332 parts (Nuclear Enterprises).

Uronic acid determination was performed on $0.02 \mathrm{ml}$ of the cartilage digest using the method of Bitter and Muir (1962). We have incubated the glucuronolactone standards with buffered papain and found no difference compared with standards containing no papain.

For DNA estimation a fluorimetric method was used, modified from Prasad and others (1972). Standards were prepared from calf thymus gland DNA (British Drug Houses). $0.2 \mathrm{ml}$ of the standards were added to $1.8 \mathrm{ml}$ of TRIS buffer pH $8.1(0.5 \mathrm{~mol} / \mathrm{l})$ and reacted with $2 \mathrm{ml}$ of ethidium bromide, $5 \mu \mathrm{g} / \mathrm{ml}$ (Sigma). The standards and the blank were incubated with papain in the same way as the cartilage explants. $0.2 \mathrm{ml}$ of the cartilage digests were incubated with $0.02 \mathrm{ml}$ RNA-ase, $40 \mu \mathrm{g} / \mathrm{ml}$ (Sigma). To each of the cartilage digests $1.8 \mathrm{ml}$ of TRIS and $2.0 \mathrm{ml}$ of ethidium bromide were added. The tubes were read on the Aminco Bowman spectrophotofluorimeter with the excitation wavelength set at $480 \mathrm{~nm}$ and the fluorescent wavelength at $580 \mathrm{~nm}$.

The control explants maintained at $4^{\circ} \mathrm{C}$ were washed in ethanol, dried to a constant weight, and digested in papain. Aliquots were used for liquid scintillation counting.

\section{Results}

The control cultures maintained at $4^{\circ} \mathrm{C}$ failed to show significant uptake of ${ }^{35} \mathrm{SO}_{4}$ (Table I). The counts registered were three times the background counts.

Table I Radioactive counts obtained after papain digestion

\begin{tabular}{|c|c|c|}
\hline Patient & $\begin{array}{l}d p m / m g \text { dry cartilage at } 2^{\circ} \mathrm{C} \\
\text { (total recorded not corrected } \\
\text { for background) }\end{array}$ & $\begin{array}{l}\text { Background } \\
\text { dpm }\end{array}$ \\
\hline $\begin{array}{l}1 \\
2 \\
3 \\
4 \\
5 \\
6 \\
7 \\
8\end{array}$ & $\begin{array}{l}33 \\
39 \\
35 \\
60 \\
75 \\
70 \\
39 \\
35\end{array}$ & $\begin{array}{l}34 \\
32 \\
48 \\
32 \\
30 \\
40 \\
45 \\
28\end{array}$ \\
\hline
\end{tabular}

One explant from each patient taken from noneroded area was maintained at $4^{\circ} \mathrm{C}$. Tissue was cultured with $35 \mathrm{SO}_{4}$ for 48 hours and treated identically to the test cultures. $\mathrm{dpm}=$ disintegrations per minute.
This suggests that these chondrocytes were inactive and that the washing in ethanol before papain digestion was effective in removing the sulphate that had not been incorporated into proteoglycans.

\section{VIABILITY OF CULTURES}

We have previously shown (Jacoby and Jayson, 1975b) that human cartilage can be maintained in organ culture by this technique for at least 8 days. At that time the cells appear viable as judged by light microscopy, electron microscopy, and uptake of ${ }^{35} \mathrm{SO}_{4}$. It is reasonable to assume that in the present study the explants were alive at the end of the 72-hour culture period.

DNA AND URONIC ACID CONTENT OF CARTILAGE (Figs. 1, 2; Table II).

Forty explants were obtained from 8 patients. Fifteen of the explants were taken immediately below the invading rheumatoid pannus and 25 from macroscopically normal areas. The uronic acid and DNA are expressed in $\mu \mathrm{g} / 50$ cryostat sections (Table II). These results show a significant reduction in the mean uronic acid content of eroded cartilage compared with

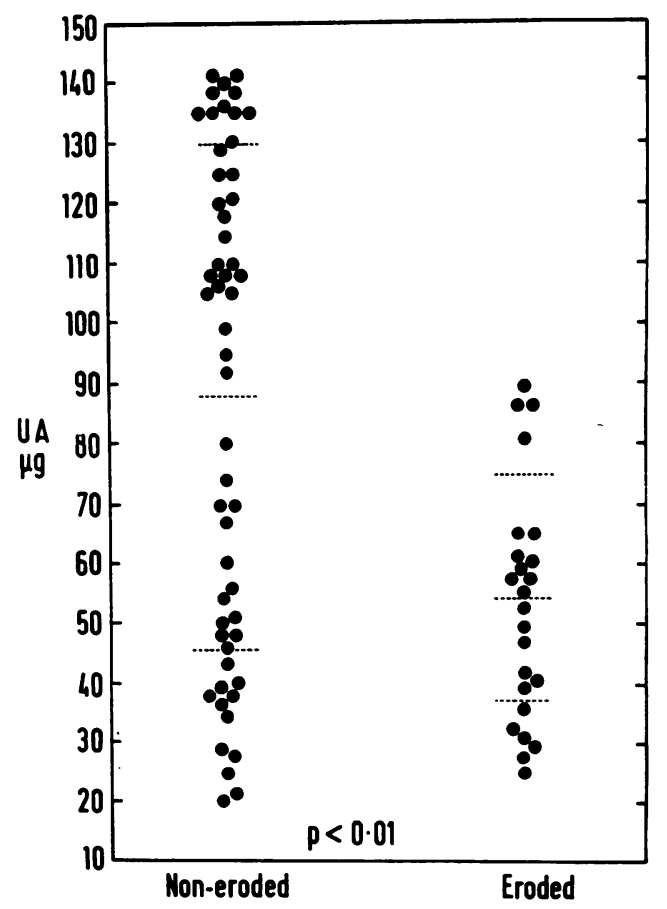

FIG. 1 Uronic acid (UA) content of 50 cryostat sections taken from eroded and nonerod'd cartilage explants. One explant furnished up to three groups of 50 cryostat sections. The 56 noneroded cartilage measurements were obtained from 25 explants and the 24 eroded cartilage measurements were obtained from 15 explants. 


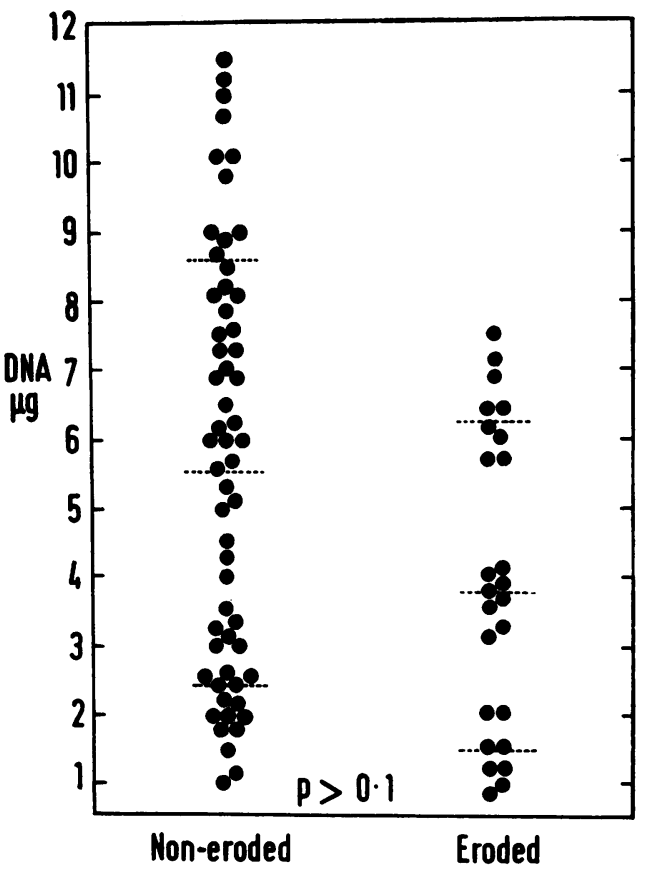

FIG. 2 DNA content of 50 cryostat sections taken from eroded and noneroded cartilage explants

noneroded cartilage. The mean DNA content was also less but the difference was not significantly different.

${ }^{35} \mathrm{SO}_{4}$ UPTAKE BY THE CARTILAGE (Figs. 3, 4; Table III)

The incorporation of ${ }^{35} \mathrm{SO}_{4}$ into the sulphated glycosaminoglycan of cartilage matrix was significantly greater in the explants taken from eroded cartilage than from noneroded sites (Table III). The results are expressed as dpm (disintegrations per minute) divided by the DNA content or uronic acid content per 50 microtome sections. Uronic acid is a measure of the chondroitin sulphate, into which the ${ }^{35} \mathrm{SO}_{4}$ is incorporated, and is one of the two important polysaccharide side chains of the proteoglycan.

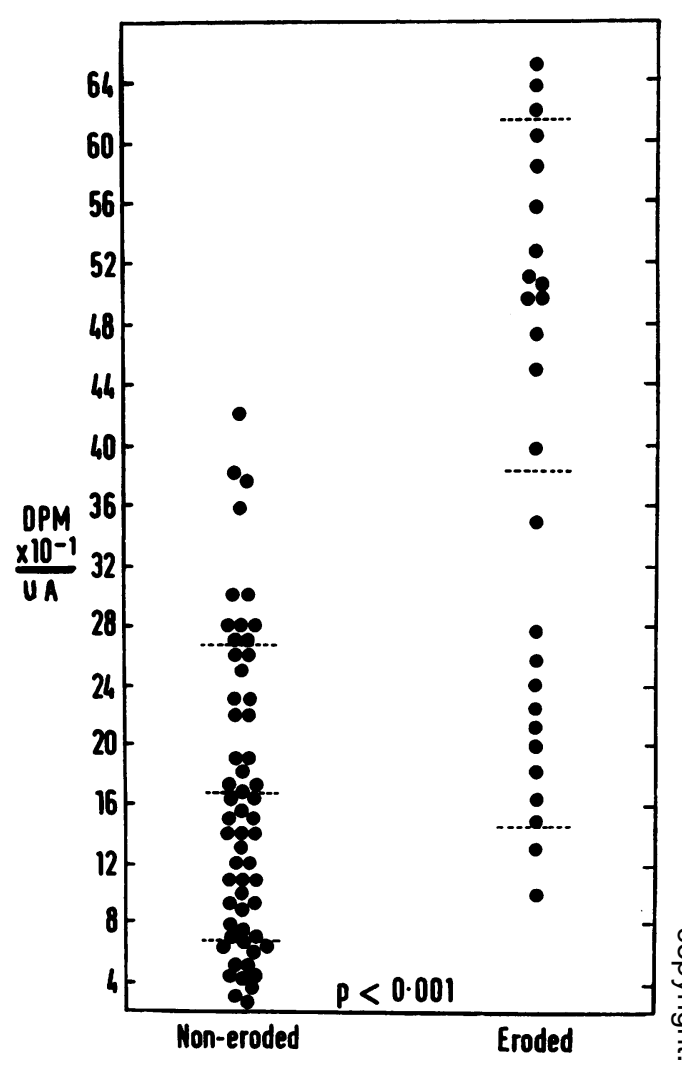

FIG. 3 The dpm/uronic acid measurements in 50 cryostat sections taken from eroded and noneroded cartilage explants

\section{Discussion}

Living cartilage explants may be maintained in organ culture for a period of several days (Poole and others, 1973; Millroy and Poole, 1974; Jacoby and Jayson, 1975a, b). All these workers have used an identical model to study the behaviour of living cartilage in organ culture. The cartilage was obtained at synovectomy since the joint surfaces showed both eroded and noneroded cartilage. In patients undergoing total knee replacement for rheumatoid arthritis the cartilage is virtually

Table II Mean values of DNA and uronic acid content of cartilage explants from subpannus and noneroded regions of rheumatoid joints

\begin{tabular}{|c|c|c|c|}
\hline & No. of specimens & $\mu g$ uronic acid/50 sections & $\mu g D N A / 50$ sections \\
\hline $\begin{array}{l}\text { Cartilage from eroded areas (subpannus) } \\
\text { Cartilage from noneroded areas } \\
\text { Values for 't' comparing the two types of } \\
\text { cartilage }\end{array}$ & $\begin{array}{l}15 \\
25\end{array}$ & $\begin{array}{l}52(19) \\
91(44) \\
-3 \cdot 17\end{array}$ & $\begin{array}{l}3 \cdot 9(2 \cdot 1) \\
5.6(3 \cdot 1) \\
1 \cdot 83\end{array}$ \\
\hline Significance & & $P<0.01$ & NS \\
\hline
\end{tabular}

The difference between the two types was tested; ' $t$ ' values and the significance are shown. Standard deviation in parentheses. 


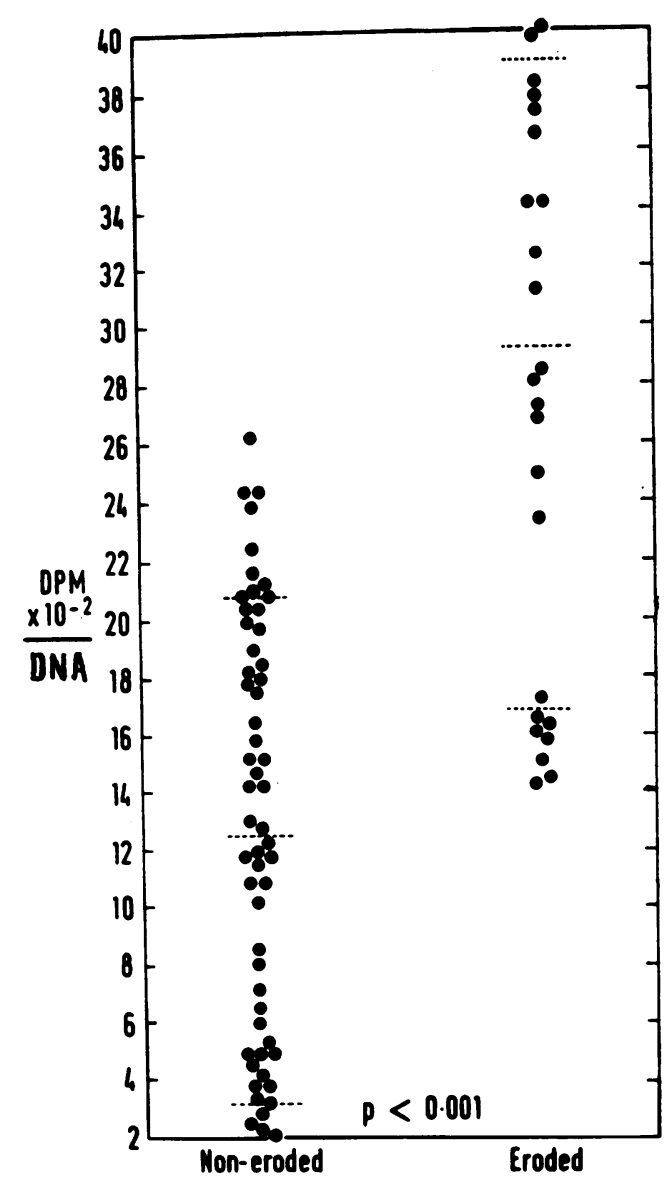

FIG. 4 The dpm/DNA measurements in 50 cryostat sections taken from eroded and noneroded cartilage explants

completely destroyed and we have not been able to obtain suitable material for culture.

This study has examined only one parameter of chondrocyte function, the incorporation of ${ }^{35} \mathrm{SO}_{4}$ into proteoglycan. However, this is an important action and is a measure of proteoglycan synthesis (Dziewiatkowski, 1966). The analysis of uronic acid content only relates to chrondroitin sulphate and not to keratan sulphate. The distribution of the ${ }^{35} \mathrm{SO}_{4}$ between these two polyanions is not of great importance in this context, even though Mankin and Lippiello (1971) have shown that osteoarthrotic chondrocytes manufacture more chondroitin sulphate than normal areas.

Cartilage obtains many of its physical properties from the intracellular proteoglycan. The turnover of this matrix component has been measured by Mankin and Lippiello (1969) and Maroudas and Evans (1974). However, it has not been studied in rheumatoid arthritis. Proteoglycan protects the chondrocytes when the cartilage matrix has been damaged by enzymes (Millroy and Poole, 1974). This study has shown that where the matrix has been eroded over them, the chondrocytes synthesize more proteoglycan than in noneroded cartilage. This could be a protective phenomenon. Maroudas and Evans (1974) have suggested that the diffusion of sulphate into the cartilage is inversely proportional to the glycosaminoglycan content. Since this is lower in the eroded cartilage, this might account for some of the observed differences that were found.

Not only the depth from the joint surface but also the region of the joint from which the cartilage was removed may be important. The glycosaminoglycan content varies from one area to another (Jacoby and Jayson, 1975a) and with increasing depth from the surface (Stockwell and Scott, 1967). As far as possible we matched the sections from eroded cartilage with equivalent sections from normal areas. The depth from the surface and the region from which the two types of cartilage were obtained were equivalent.

In this paper we have been comparing the incorporation of radiosulphate into proteoglycan which is an accummulative process. The diffusion of ions into cartilage is a passive process, which does not depend on living chondrocytes (Maroudas and Evans, 1974). These workers have shown that incorporation is linear up to 8 hours and then falls after this time. The rate of diffusion is not important in this experiment as long as this is similar in the test and control systems. The incubation time with ${ }^{35} \mathrm{SO}_{4}$ is considerably longer than that used by previous workers

Table III Mean values of the radioactivity (dpm) per 50 sections, related to DNA and uronic acid

\begin{tabular}{|c|c|c|c|}
\hline & No. of specimens & $d p m / D N A \mu g$ per 50 sections & $d p m /$ uronic $\mu g$ per 50 sections \\
\hline $\begin{array}{l}\text { Cartilage from eroded areas } \\
\text { (subpannus) }\end{array}$ & 15 & $2811(990)$ & $384(183)$ \\
\hline $\begin{array}{l}\text { Cartilage from noneroded } \\
\text { areas }\end{array}$ & 25 & $1288(700)$ & $171(101)$ \\
\hline $\begin{array}{l}\text { Values for ' } t \text { ' comparing the } \\
\text { two types of cartilage }\end{array}$ & & $5 \cdot 51$ & $4 \cdot 6$ \\
\hline Significance & & $P<0.001$ & $P<0.001$ \\
\hline
\end{tabular}

The difference between the two types of cartilage was tested; ' $t$ ' and $P$ values are shown. 
(Mankin and Lippiello, 1970; Maroudas and Evans, 1974). Preliminary experimentation had shown that this 48-hour period gave the best differential in counts per minute between normal and diseased cartilage. This incorporation was not passive diffusion of sulphate ions into the tissue since explants maintained at $4^{\circ} \mathrm{C}$ for the same period did not show any pseudo incorporation.

These results indicate that the eroded cartilage is metabolically more active than the noneroded areas. It is possible that this is a protective phenomenon since the chondrocytes are inaccessible to potentially lethal macromolecules if they are surrounded by proteoglycan (Millroy and Poole, 1974). Furthermore, proteoglycan depleted cartilage is more easily compressed under load than normal (Freeman and Kempson, 1973), therefore, in eroded cartilage, the chondrocytes are more liable to become damaged as the proteoglycan content delcines.

The increase in proteoglycan synthesis could also be seen as a negative feedback response to proteoglycan depletion. It is possible that in osteoarthrosis (Mankin and Lippiello, 1970) and rheumatoid arthritis the chondrocytes are able to detect proteo- glycan depletion in the surrounding matrix. There is experimental evidence to suggest that chondrocytes can detect proteoglycan loss. Fitton-Jackson (1967) showed a similar response in embryonic chick bone cartilage exposed to hyaluronidase in the culture medium. Also Bosmann (1968) found an increased synthesis of proteoglycan in embryonic chick cartilage exposed to papain in the culture medium. Although the chondrocytes synthesized more proteoglycan after being exposed to these enzymes, the proteoglycan reappeared more rapidly in the medium. This was in spite of the fact that the enzyme was no longer in contact with the explants. It is therefore possible that in eroded rheumatoid cartilage, proteoglycan manufacture is not only greater than the noneroded cartilage, but more inefficient. If this is indeed the case, perhaps on theoretical grounds treatment of rheumatoid erosions should be designed to reduce the breakdown of newly formed proteoglycan, rather than stimulate the chondrocytes to produce more proteoglycan.

We wish to thank the Dr. Hadwen Trust and the Arthritis and Rheumatism Council for their support, and Mrs. Carol Watson for technical assistance.

\section{References}

Biggers, J. D., Gwatkin, R. D., ANd Heyner, S. (1961) Exp. Cell Res., 25, 41 (Growth of embryonic avian and mammalian tibiae on a relatively simple chemically defined medium)

BitTer, T., AND MuIr, H. M. (1962) Ann. Biochem., 4, 330 (A modified uronic acid carbazole reaction)

Bollet, A. J., AND NANCE, J. L. (1966) J. clin. Invest., 45, 1170 (Biochemical findings in normal and osteoarthritic articular cartilage)

Bosmann, H. B. (1968) Proc. roy. Soc. B, 169, 399 (Cellular control of macromolecular synthesis)

Dingle, J. T., Fell, H. B., AND Lucy, J. A. (1966) Biochem. J., 98, 173 (Synthesis of connective tissue components)

Dziewiatkowski, D. D. (1966) J. biol. Chem., 223, 239 (Some aspects of the metabolism of chondroitin sulphate ${ }^{35} \mathrm{~S}$ in the rat)

FitTon-JACKSON, S. (1967) Biochem. J., 104, 13P (Factors concerned in the maintenance of the synthetic balance of intercellular macromolecules)

Freeman, M. A. R., And Kempson, G. E. (1973) In ‘Adult Articular Cartilage', ed. M. A. R. Freeman. Pitman, London.

JACOBY, R. K., AND JAYSON, M. I. V. (1975a) J. Rheumatol., 2, 270 (Organ culture of adult human articular cartilage I) (1975b) Ibid., 2, 280 (Organ culture of adult human articular cartilage II)

Mankin, H. J., AND LipPiello, L. (1969) J. Bone Jt Surg., 51A, 1591 (The turnover of adult rabbit articular cartilage) (1970) Ibid., 52A, 424 (Biochemical and metabolic abnormalities in articular cartilage from osteoarthritic human hips)

_- - (1971) J. clin. Invest., 50, 1712 (Glycosaminoglycan of normal and arthritic cartilage)

MAROudAS, A. (1970) Biophys J., 10, 365 (Distribution and diffusion of solutes in articular cartilage)

-, AND Evans, H. (1974) Biochim. biophys. Acta, 338, $265\left(\mathrm{SO}_{4}\right.$ diffusion and incorporation into human articular cartilage)

Millroy, S. J., ANd Poole, A. R. (1974) Ann. rheum. Dis., 33, 500 (Pig articular cartilage in organ culture)

Poole, A. R., Barratt, M. E. J., AND Fell, H. B. (1973) Int. Arch. Allergy, 44, 469 (The role of soft connective tissue in the breakdown of pig articular cartilage cultivated in the presence of complement sufficient antiserum to pig erythrocytes. II. Distribution of immunoglobulin $\mathrm{G}(1 \mathrm{gG})$.

Prasad, A. S., DeMouchelle, E., Koniuch, D., And Oberleas, D. (1972) J. Lab. clin. med., 80, 598 (A simple fluorimetric method for the determination of RNA and DNA in tissues)

ReYNOLDS, J. (1972) In 'Biochemistry and Physiology of Bone', Vol. 1, ed. G. Bourne. Academic Press, New York

Stockwell, R. A., AND Scott, J. E. (1967) Nature, 215, 1376 (Distribution of acid glycosaminoglycans in human articular cartilage)

Trowell, O. A. (1954) Exp. Coll. Res., 6, 246 (A modified technique for organ culture in vitro) 